TITLE:

\title{
Aluminum oxide thin films prepared by chemical vapor deposition from aluminum 2- ethylhexanoate
}

$\operatorname{AUTHOR}(S):$

MARUYAMA, T; NAKAI, T

CITATION:

MARUYAMA, T ... [et al]. Aluminum oxide thin films prepared by chemical vapor deposition from aluminum 2-ethylhexanoate. APPLIED PHYSICS LETTERS 1991, 58(19): 2079-2080

\section{ISSUE DATE:}

1991-05-13

URL:

http://hdl.handle.net/2433/43522

\section{RIGHT:}

Copyright 1991 American Institute of Physics. This article may be downloaded for personal use only. Any other use requires prior permission of the author and the American Institute of Physics. 


\title{
Aluminum oxide thin films prepared by chemical vapor deposition from aluminum 2-ethylhexanoate
}

\author{
Toshiro Maruyama and Tsuyoshi Nakai \\ Department of Chemical Engineering, Faculty of Engineering, Kyoto University, Kyoto 606, Japan
}

(Received 29 October 1990; accepted for publication 13 March 1991)

\begin{abstract}
Aluminum oxide thin films were prepared by a low-temperature atmospheric-pressure chemical vapor deposition method. The raw material was aluminum 2-ethylhexanoate, which is nontoxic and easy to handle. At a reaction temperature above $480^{\circ} \mathrm{C}$, an amorphous film can be obtained on glass and silicon (100) substrates. The reaction temperature and the deposition rate are comparable to the corresponding values in the low-temperature chemical vapor depositions of $\mathrm{Al}_{2} \mathrm{O}_{3}$. In addition, the deposition can be carried out in air. Aluminum 2-ethylhexanoate appears to offer a viable alternative to alkylaluminum, aluminum $\beta$-diketonate, and alkoxide for low-temperature $\mathrm{Al}_{2} \mathrm{O}_{3}$ production.
\end{abstract}

Aluminum oxide thin films are widely used in a variety of applications including gate insulator and passivation layer on $\mathrm{Si}$ in semiconductors. High quality $\mathrm{Al}_{2} \mathrm{O}_{3}$ layers have traditionally been prepared by rf magnetron sputtering, reactive dc sputtering, or reactive vacuum evaporation. An alternative is to deposit $\mathrm{Al}_{2} \mathrm{O}_{3}$ by chemical vapor deposition (CVD) methods. Various CVD methods have been proposed, for example high-temperature (800-1100 $\left.{ }^{\circ} \mathrm{C}\right) \mathrm{CVD}$ of the $\mathrm{AlCl}_{3}-\mathrm{CO}_{2}-\mathrm{H}_{2}$ system ( $\mathrm{CO}_{2}$ method), ${ }^{1}$ metalorganic chemical vapor deposition of alkylaluminum, such as $\mathrm{Al}\left(\mathrm{CH}_{3}\right)_{3}-\mathrm{O}_{2}$ system $\left(350-500^{\circ} \mathrm{C}\right)$, CVD of alkoxides, such as $\mathrm{Al}\left(i-\mathrm{OC}_{3} \mathrm{H}_{7}\right)_{3}$ (aluminum-tri-isopropoxide, $\left.420-600^{\circ} \mathrm{C}\right),{ }^{2}$ and CVD of $\beta$-diketonate $\left(420^{\circ} \mathrm{C}\right){ }^{3}$ The main difficulty of the $\mathrm{CO}_{2}$ method is the ready nucleation of $\mathrm{Al}_{2} \mathrm{O}_{3}$ in the gas phase. The $\mathrm{Al}_{2} \mathrm{O}_{3}$ crystal tends to form needles or other odd shapes. In addition, the $\mathrm{CO}_{2}$ method often suffers from corrosion of the substrate and reactor vessels caused by the byproducts of hydrogen chloride in the high reaction temperaturc. For the low-temperaturc $\left(350-600^{\circ} \mathrm{C}\right) \mathrm{CVD}$ methods, obtaining of the metalorganic source materials can be difficult. They are usually expensive or toxic and are not readily available.

In this letter, aluminum 2-ethylhexanoate [Al $\left.\left(\mathrm{C}_{7} \mathrm{H}_{15} \mathrm{COO}\right)_{3}\right]$ is proposed as a precursor for obtaining $\mathrm{Al}_{2} \mathrm{O}_{3}$ films by the low-temperature atmospheric-pressure CVD method. Aluminum 2-ethylhexanoate is nontoxic. It is not expensive and readily available.

Aluminum 2-ethylhexanoate (Nihon Kagaku Sangyo Co., Ltd.) of reagent grade was used as the source material. It is easy to handle in solid form (powder) at room temperature. It was heated at a temperature of $280-300^{\circ} \mathrm{C}$ and the generated gas was entrained by nitrogen carrier gas. The flow rate of the carrier gas was $0.3-0.6 \mathrm{l} / \mathrm{min}$.

Borosilicate glass plates, quartz glass plates, and silicon (100) single-crystal wafers were used as the substrates. The substrate was placed in the reactor heated by an external electric furnace. The reaction temperature ranged from 480 to $700^{\circ} \mathrm{C}$. The depositions were carried out at atmospheric pressure in air atmosphere and in an inert (nitrogen) atmosphere.

The composition of the film was measured by $\mathrm{x}$-ray photoelectron spectroscopy (XPS). The infrared spectra were obtained by means of a Fourier transform infrared spectrometer (Shimadzu FTIR-4300). The samples were prepared by depositing films about $800 \mathrm{~nm}$ thick on silicon single-crystal substrates. The crystallinity of the film was analyzed by the x-ray diffraction method with $\mathrm{Cu} K \alpha$ radiation. The optical transmittance of the film was obtained by means of a multipurpose recording spectrophotometer. A blank glass substrate was inserted into the reference beam path of the spectrophotometer.

The film could be grown in both inert (nitrogen) and air atmosphere. This fact means that oxygen in $\mathrm{Al}_{2} \mathrm{O}_{3}$ orginates not from $\mathrm{O}_{2}$ gas but from oxygen combined with the metal in the raw material. Deposition in an inert atmosphere is also effective to prevent burning of the source gas which occurs at the reaction temperature above $550^{\circ} \mathrm{C}$ in air. Hence the data for the reaction temperature above $600{ }^{\circ} \mathrm{C}$ are based on the measurements in an inert (nitrogen) atmosphere.

The lower limit of the reaction temperature was $480^{\circ} \mathrm{C}$. X-ray photoclectron spectroscopy showed that the film was stoichiometric $\mathrm{Al}_{2} \mathrm{O}_{3}$. The films were transparent and showed no apparent peeling. The optical transmittance of the 110-nm-thick film was more than $98 \%$ in the wavelength range of $330-1000 \mathrm{~nm}$.

Table I shows the atomic ratio of oxygen to aluminum at various substrate temperatures. The ratio is $1.67-1.85$ for the inert atmosphere, and is about 1.66 for the air atmosphere. Thus, the oxides are near-stoichiometric $\mathrm{Al}_{2} \mathrm{O}_{3}$. A little excess of oxygen is attributable to a contamination from the gas phase in the measurements of XPS under the pressure of $\sim 3 \times 10^{-5} \mathrm{~Pa}$.

Figure 1 shows infrared absorption spectra of films deposited at three different reaction temperatures. Absorption peaks at about $1100-500 \mathrm{~cm}^{-1}$ represent the vibrations of $\mathrm{Al}_{2} \mathrm{O}_{3}$. Absorption peaks at about 3400-3200 $\mathrm{cm}^{-1}$ and $1100-1050 \mathrm{~cm}^{-1}$ represent $\mathrm{O}-\mathrm{H}$ bond vibration and $\mathrm{C}-\mathrm{O}$ bond vibration. Absorption peaks at about 2000-1250 and 700-400 $\mathrm{cm}^{-1}$ represent vibrations of water. The x-ray diffraction pattern of the film showed that the films were amorphous.

Figure 2 shows the Arrhenius plot of deposition rates, which were obtained at a source temperature of $280^{\circ} \mathrm{C}$ and a $\mathrm{N}_{2}$ flow rate of $0.3 \mathrm{l} / \mathrm{min}$. The deposition rates are of the same order of magnitude as those reported previously us- 
TABLE I. Atomic ratio of oxygen to aluminum at various reaction temperatures.

\begin{tabular}{lcc}
\hline \hline Deposition atmosphere & Reaction temperature & O/Al \\
\hline Nitrogen & 500 & 1.75 \\
& 525 & 1.67 \\
& 550 & 1.68 \\
& 600 & 1.85 \\
& 650 & 1.74 \\
Air & 500 & \\
& 525 & 1.66 \\
& 550 & 1.65 \\
\hline \hline
\end{tabular}

ing the low-temperature CVD methods. The straight lines in this figure show that the activation energy is $\sim 28.1$ $\mathrm{kJ} / \mathrm{mol}(0.291 \mathrm{eV} /$ molecule $)$.

In conclusion, aluminum oxide thin films were prepared by a low-temperature atmospheric pressure chemical vapor deposition method. The raw material was aluminum 2-ethylhexanoate, which is nontoxic and easy to handle. At

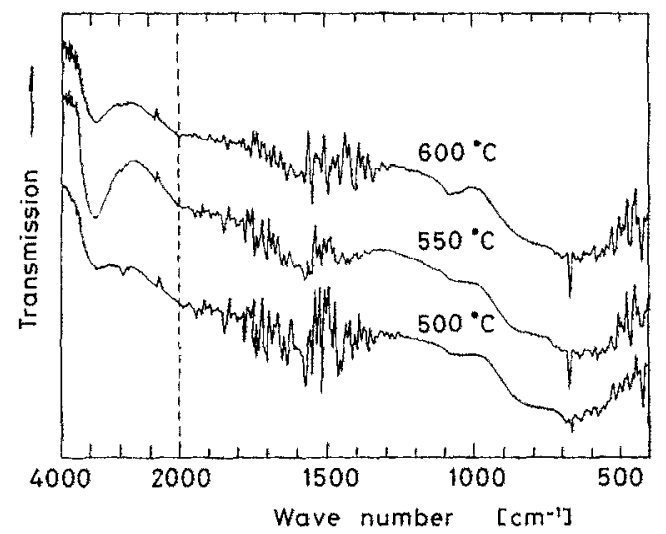

FIG. 1. IR transmission spectra of films deposited at various temperatures. (The wave number scale is linear with a scale change at 2000 $\mathrm{cm}^{-1}$.)

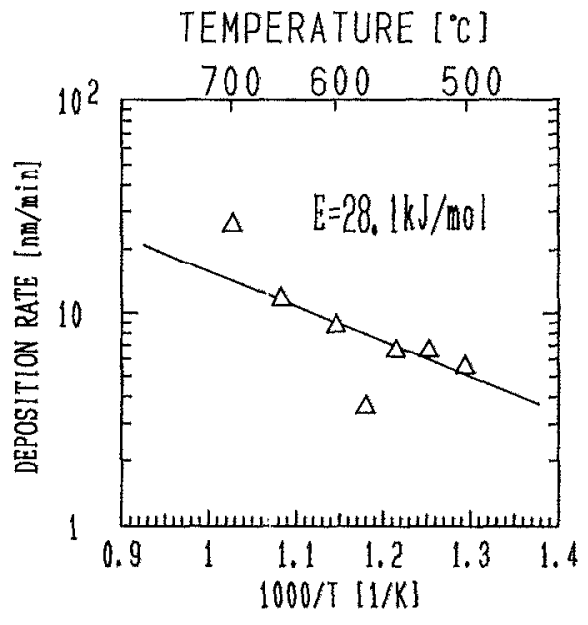

FIG. 2. Arrhenius plct of deposition rate.

a reaction temperature above $480^{\circ} \mathrm{C}$, an amorphous film can be obtained on glass and silicon (100) substrates. The reaction temperature and the deposition rate are comparable to the corresponding values in the low-temperature chemical vapor depositions of $\mathrm{Al}_{2} \mathrm{O}_{3}$. In addition, the deposition can be carried out in air. Aluminum 2-ethylhexanoate appears to offer a viable alternative to alkylaluminum, aluminum $\beta$-diketonate, and alkoxide for lowtemperature $\mathrm{Al}_{2} \mathrm{O}_{3}$ production.

This work was supported by the Japan Securities Scholarship Foundation, Nissan Science Foundation, Iketani Science and Technology Foundation, and Miyashita Research Foundation.

'B. Lux, Proc. 4th Eu,opean Conference on Chemical Vapour Deposition, Eindhoven, The Netherlands, 1983 (Philips Centre for Manufacturing Technology, Eindhoven, 1983), p. 379 .

2J. A. Aboaf, J. Electrochem. Soc. 114, 948 (1967).

${ }^{3}$ O. B. A. Ajayi, M. S. Akanni, H. D. Burrow, J. N. Lambi, O. Osasona, and B. P. Podor, Thin Solid Films 138, 91 (1986). 